\title{
Subclinical hypothyroidism in children: updates for pediatricians
}

\section{Kotb Abbass Metwalley, Hekma Saad Farghaly}

Department of Pediatrics, Faculty of Medicine, Assiut University, Assiut, Egypt

Received: 10 November, 2020

Revised: 11 December, 2020

Accepted: 12 January, 2021

Address for correspondence: Kotb Abbass Metwalley

Pediatric Endocrinology Unit, Department of Pediatrics, Faculty of Medicine, Assiut University, 71111 Assiut, Egypt

Email:kotb72@aun.edu.eg https://orcid.org/0000-0003-4763$488 \mathrm{X}$
Subclinical hypothyroidism ( $\mathrm{SH}$ ) is defined as serum thyroid-stimulating hormone (TSH) above the upper limit of the reference range in the presence of normal free T4 concentrations. Depending on the degree of TSH elevation, $\mathrm{SH}$ could be defined as mild (TSH, 4.5-10 mIU/L) or severe (TSH>10 mIU/L). While there is a general consensus to treat children with serum TSH levels above $10 \mathrm{mU} / \mathrm{L}$, the management of the mild form is uncertain and should be individualized. In this mini-review, we present a brief review of $\mathrm{SH}$ in children based on extensive literature review and long-standing clinical experience. This review provides the prevalence, causes, clinical presentation, consequences, investigation, and up-to-date therapeutic approach of SH in children. Generally, the purpose of the review is to provide pediatricians with an update of this common and continuously evolving condition.

Keywords: Subclinical hypothyroidism, Hashimoto's thyroiditis, Thyroid-stimulating hormone, Thyroid autoantibodies, Levothyroxine

\section{Highlights}

Subclinical hypothyroidism (SH) is defined as serum levels of thyroid-stimulating hormone (TSH) above the upper limit of the reference range in the presence of normal concentrations of free T4. Hashimoto's thyroiditis (HT) is the most common cause of SH, especially among older children and adolescents (age range, $8-18$ years). While there is an agreement to treat children with serum TSH levels above $10 \mathrm{mU} / \mathrm{L}$, the treatment of the mild form (TSH levels between 4.5 and $10 \mathrm{mU} / \mathrm{L}$ ) is uncertain and should be individualized.

\section{Introduction}

Subclinical hypothyroidism (SH) is a biochemical situation characterized by serum thyroid-stimulating hormone (TSH) levels above the upper limit of the reference range for the assay with free T4 (fT4) values within the reference interval of the assay. ${ }^{1)}$ This condition is also known as compensated hypothyroidism or isolated hyperthyrotropinemia. $\mathrm{SH}$ is considered to be a mild form of thyroid failure by some investigators due to the inverse loglinear relationship between TSH and thyroid hormones. ${ }^{2}$ Depending on the degree of TSH elevation, $\mathrm{SH}$ could be classified as mild (TSH, $4.5-10 \mathrm{mIU} / \mathrm{L}$ ) or severe $(\mathrm{TSH}>10 \mathrm{mIU} / \mathrm{L}){ }^{3)}$

\section{Epidemiology}

SH prevalence in adults is reported to be $4 \%-20 \%$ and is higher in females, in the elderly, and in whites. ${ }^{4} \mathrm{SH}$ in children is less common, with a prevalence that has been reported to range around $\left.1.7 \%{ }^{5}\right)$ 


\section{Etiology}

\section{Hashimoto's thyroiditis}

Hashimoto's thyroiditis (HT) is the most common cause of SH, especially among older children and adolescents (age range, $8-18$ years). ${ }^{6}$ HT is characterized by the existence of thyroid autoantibodies (antithyroid peroxidase [TPO Ab] and antithyroglobulin [TG Ab]) with or without goiter. ${ }^{7)}$ Patients with HT may develop subclinical or overt hypothyroidism depending on the intensity of the immunological injury.

\section{Genetic mutations and genetic syndromes}

\section{1) Mutations in the TSH-receptor}

Heterozygous mutations in the gene encoding TSHreceptor have been reported in $11.4 \%-29.0 \%$ of children with nonautoimmune $\mathrm{SH}^{9,10)}$ These mutations are associated with a wide range of thyroid dysfunction, from severe congenital hypothyroidism due to thyroid hypoplasia to $\mathrm{SH}^{11)}$

\section{2) Dual oxidase 2 mutations}

Mutations in the gene encoding dual oxidase 2 (DUOX2) are associated with defects in iodide organification and are also reported to cause persistent $\mathrm{SH}^{12)}$

\section{3) Down syndrome}

A high prevalence of $\mathrm{SH}$ has been associated with Down syndrome (DS) ranging from $25.3 \%$ to $60.0 \% .{ }^{13)} \mathrm{HT}$ is more likely to present with $\mathrm{SH}$ in DS compared to the general population. $^{14)}$

\section{4) Turner syndrome}

In patients with Turner syndrome, $\mathrm{SH}$ is also frequent, with a prevalence of up to $58 \%$, and is mainly related to the presence of $\mathrm{HT}^{15)}$

\section{Persistent neonatal hyperthyrotropinemia}

A lower TSH cutoff at neonatal screening may result in an increased incidence of both mild and transient forms of hypothyroidism. In the neonatal period, $\mathrm{SH}$ can be defined by a TSH value between 6 and $20 \mathrm{mIU} / \mathrm{L}$ and normal FT4 levels. ${ }^{16)} \mathrm{SH}$ in the neonatal period is more common in some high-risk babies such as preterm or sick neonates, small for gestational age infants, neonates born after in vitro fertilization, and infants from multiple pregnancies. Other causes of $\mathrm{SH}$ include syndromic babies, those with congenital anomalies, corticosteroid treatment during pregnancy or in the neonatal period, and maternal thyroid abnormalities. ${ }^{17)}$

\section{Obesity}

Studies indicate that SH may be detected in around 10\%-23\% of children with obesity. ${ }^{18)} \mathrm{SH}$ seems to be a sequela, rather than a cause of weight gain. Accordingly, several studies have documented that TSH levels normalized after participation in weight-loss programs. ${ }^{19)}$

\section{Iron deficiency anemia}

Gökdeniz et al. ${ }^{20)}$ reported that $16.6 \%$ of children with iron deficiency anemia (IDA) had SH, and Metwalley et al. ${ }^{21)}$ reported that primary school children with IDA were prone to develop SH and intellectual dysfunction.

\section{Nephrotic syndrome}

Afroz et al. ${ }^{22)}$ reported that children with Nephrotic syndrome (NS) commonly experience a state of SH during the active phase of proteinuria without symptoms of hypothyroidism. NS may trigger the onset of hypothyroidism or aggravate pre-existing $\mathrm{SH}$, increasing requirements of $\mathrm{L}-\mathrm{T} 4$ supplementation because of urinary loss of free and protein-bound thyroid hormones. ${ }^{23)}$

\section{Idiopathic $\mathrm{SH}$}

Children with SH without clear etiology are classified as having idiopathic $\mathrm{SH}^{24)}$ In most cases, however, thyroid function remains relatively stable for long periods with a lower risk of deterioration in thyroid function over time. ${ }^{25)}$

\section{8. lodine deficiency or excess}

Low iodine intake for a prolonged period may result in mild to severe $\mathrm{SH}$, as well as goiter and overt hypothyroidism. ${ }^{26)}$ Additionally, population studies indicate that SH may also occur in subjects with high iodine intake. ${ }^{27)}$

\section{9. lonizing radiation}

Children exposed to ionizing radiation either by therapy or in the environment may be susceptible to developing $\mathrm{SH}^{28)}$

\section{Medications}

Amiodarone ${ }^{29)}$ and interferon (IFN)- $a^{30)}$ are examples of drugs that may impair thyroid function, causing $\mathrm{SH}$. Additionally, $\mathrm{SH}$ is frequently reported in children treated with antiepileptic drugs (valproic acid, phenytoin, carbamazepine, and phenobarbital). ${ }^{31)}$

\section{Euthyroid sick syndrome}

A child with acute illness may have a transient decrease in thyroid hormone secretion. During the recovery stage, a transient increase in TSH is the normal mechanism for restoring normal thyroid hormone levels, and TSH will return to normal 
within a short period of time. ${ }^{32)}$ Thus, TSH levels should be measured at a 2- to 3-month interval to rule out laboratory error or transient increase in TSH levels. ${ }^{33)}$

\section{Laboratory pitfalls}

High TSH levels with normal fT4 may result from laboratory interference. ${ }^{34)}$ Six main types of interference in thyroid function testing have been identified: macro-TSH, biotin, antistreptavidin antibodies, antiruthenium antibodies, TH autoantibodies, and heterophilic antibodies. ${ }^{35)}$ Macro-TSH is characterized by high-molecular-weight complexes of TSH (mainly bound to IgG) with low bioactivity that accumulate in the circulation because of slow clearance and can be recognized by available immunoassays as hyperthyrotropinemia. Patients with macro-TSH have elevated serum TSH and normal FT4 levels similar to $\mathrm{SH}^{36)}$

\section{Physiological variation}

SH levels in normal children tend to vary during the day as well as over time. ${ }^{37)}$ TSH secretion follows circadian rhythms with the lowest level in the late afternoon and highest level between midnight and $4 \mathrm{AM}^{38)}$ In adolescent females, a transient increase in TSH levels may occur during the midmenstrual cycle. ${ }^{39)}$ Moreover, sleep deprivation may be associated with elevated $\mathrm{TSH}^{40)}$

\section{Clinical manifestations}

The clinical manifestation of SH may vary from no manifestations to full-blown thyroid dysfunction. This may be related to age, the sensitivity of patients to thyroid hormone

\section{Table 1. Work up of subclinical hypothyroidism in children}

History
- Birth history
- Family history of autoimmune disease
- Genetic disorders
- History of radiation
- Drugs
- lodine excess or deficiency
- Symptoms of hypothyroidism
Physical examination
- Goiter
- Growth parameters (weight, height, and body mass index)
- Vital signs (heart rate and blood pressure)
- Signs of hypothyroidism
- Syndromic features
Investigations
- Routine laboratory test
- Follow-up of thyroid function test
- Thyroid autoantibodies
- Thyroid ultrasound
- Lipid profile

deficiency severity, and the duration of SH. ${ }^{5)}$ The abnormalities most frequently associated in the pediatric population are goiter, weight gain, sleepiness, weakness, anemia, and increased cholesterol levels. ${ }^{1)}$ The severity of symptoms is not always strictly associated with TSH levels."

\section{Workup and diagnosis (Table 1)}

SH diagnosis requires measurement of serum TSH and fT4. ${ }^{3)}$ Confirmatory assay of TSH and fT4 should be performed within 2-3 months. ${ }^{5}$ ) The presence of thyroid autoantibodies (TPO $\mathrm{Ab}$ and/or TG $\mathrm{Ab}$ ) and/or the demonstration of a hypoechoic pattern of the gland by ultrasound assist in the diagnosis of HT. The typical ultrasound pattern may be present before the appearance of thyroid antibodies. ${ }^{41)}$ Thyroid ultrasound has been established as a useful tool in the investigation of persistent $\mathrm{SH}$, especially when no clear causes are identified. Furthermore, high TSH levels in children with a thyroid nodule may be used as a predictor of thyroid malignancy; therefore, thyroid ultrasound examination is an important tool in the follow-up of both treated and untreated SH patients. ${ }^{1,42)}$

\section{Consequences of long-standing untreated SH in children}

\section{Cardiac functions}

SH in children has been reported to be associated with an increased risk of hypertension. ${ }^{43)}$ Regarding ventricular function in children with $\mathrm{SH}$, recent studies have revealed conflicting results. ${ }^{44)}$

\section{Endothelial function and epicardial fat thickness}

Endothelial dysfunction is an early and reversible event of vascular affection and has been used to predict future coronary artery disease prior to atherosclerotic changes. ${ }^{45)}$ Flowmediated dilation (FMD) is a noninvasive ultrasound method currently recognized as a useful technique for the evaluation of endothelial function. ${ }^{45)}$ Moreover, epicardial fat thickness (EFT) is a sensitive and reliable marker of cardiovascular risk and has become an emerging target for medical interventions. ${ }^{46)}$ Only one study that we are aware of, conducted by Farghaly et al., ${ }^{47}$ has evaluated FMD and EFT. Their evaluation included 32 children with mild SH caused by HT. The authors reported higher EFT and lower FMD in the studied children compared with controls, and EFT was associated with FMD responses.

\section{Lipid profile}

Among children with untreated SH, mild abnormalities in lipid profile have been reported in the form of slight decreases in high-density lipoprotein-cholesterol (HDL-C) and mild increases in triglyceride/HDL-C ratio. ${ }^{48}$ In addition, a higher 
atherogenic index has been reported by Farghaly et al. ${ }^{47)}$ in children with mild SH caused by HT.

\section{Insulin resistance}

The current studies regarding the relationship between $\mathrm{SH}$ and insulin resistance provide contrasting results. ${ }^{48)}$

\section{Cognitive function}

The available data on cognitive function in children with $\mathrm{SH}$ showed that cognitive scores, attention level, and verbal fluency were affected in children with $\mathrm{SH}^{49)}$

\section{Growth and bone density}

$\mathrm{SH}$ has been reported not to be associated with alterations in growth, bone mineral status and bone maturation in children. ${ }^{49)}$

\section{The natural history of SH}

Predictors of progression to overt hypothyroidism include increasing age, female gender, presence of goiter, presence of positive TPO Abs, high TSH levels at diagnosis, family history of autoimmune thyroid disease, and the presence of other autoimmune conditions (i.e., celiac disease) or genetic syndromes (i.e., DS and TS) ${ }^{14,15)}$ The most important factor affecting the natural history of $\mathrm{SH}$ is its etiology.

\section{Treatment (Table 2)}

Disagreement exists over whether to treat children with SH and the cutoff point to use for the decision to treat. ${ }^{1)}$ The optimal management of SH children should take into consideration the age of the child, clinical and biochemical abnormalities, the degree of increase of TSH level, the etiology, duration of thyroid dysfunction, and the presence of syndromes. Management should be individualized.5) Approval for treating children with serum TSH levels higher than $10 \mathrm{mU} / \mathrm{L}$ has been

\section{Table 2. Recommendation of treatment with L-T4 in children} with $\mathrm{SH}$

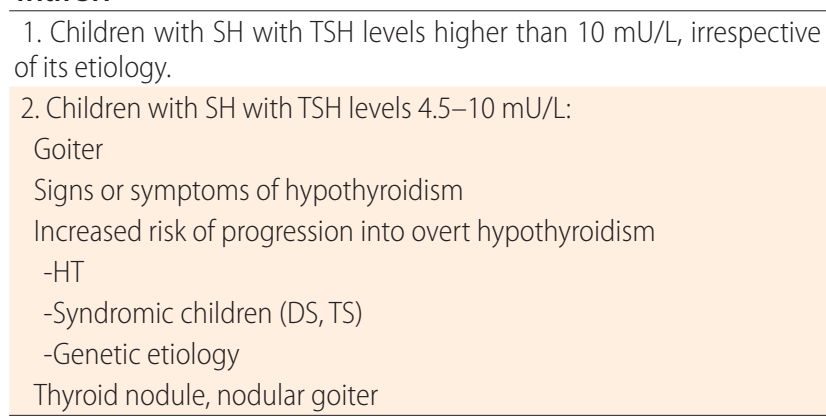

SH, subclinical hypothyroidism; TSH, thyroid-stimulating hormone; DS, Down syndrome; TS, turner syndrome; HT, Hashimoto's thyroiditis. issued. This approval is irrespective of etiology and applies especially to children with HT and progressive worsening of thyroid function over time. However, treatment of mild forms of SH (TSH, 4.5-10 mU/L) is uncertain and should be individualized. ${ }^{5)}$ In subjects with mild $\mathrm{SH}$ without symptoms or signs of hypothyroidism, regular assessment of TSH and fT4 levels every 6 months and thyroid autoantibodies and thyroid ultrasound yearly are recommended. This is particularly necessary for those with chromosomal abnormalities (TS and DS) or autoimmune disorders with the increased risk of progression into overt hypothyroidism. ${ }^{5}$

In neonates, if venous TSH levels are persistently above 20 $\mathrm{mIU} / \mathrm{L}$ with normal fT4 levels, initiation of $\mathrm{L}-\mathrm{T} 4$ treatment is advisable. However, if TSH levels are between 6 and $20 \mathrm{mIU} /$ $\mathrm{L}$ with normal fT4 levels, the decision to start treatment should be individualized. ${ }^{16,17)}$ In children with IDA associated with SH, studies have reported that children with TSH levels $>10 \mathrm{mIU} /$ $\mathrm{L}$ may benefit from L-T4 treatment which provides a desirable treatment response to iron replacement. ${ }^{20)}$ In children with NS combined with SH, L-T4 therapy may be used to avoid deterioration of thyroid function and development of overt hypothyroidism and to alleviate the deleterious effect of thyroid hormone deficiency on body homeostasis and development of overt hypothyroidism. ${ }^{23)}$ Treatment with L-T4 should be advised for children using medications, such as antiepileptic medications and IFN $\alpha$, with a TSH level $>10 \mathrm{mIU} / \mathrm{L}$ until drugs are stopped. ${ }^{30,31)}$ Last, children with persistent $\mathrm{SH}$ and diffuse or nodular goiter should be treated with $\mathrm{L}-\mathrm{T} 4$ replacement with the aim of normalizing serum TSH levels to protect against the development of thyroid carcinomas. ${ }^{50)}$

\section{Conclusions}

$\mathrm{SH}$ is a common disorder in children most frequently caused by HT. However, genetic mutations, IDA, drugs, NS, idiopathic $\mathrm{SH}$, and obesity are important causes of $\mathrm{SH}$ in children. While there is approval to treat children with serum TSH levels above $10 \mathrm{mU} / \mathrm{L}$, the treatment of the mild form (TSH levels between 4.5 and $10 \mathrm{mU} / \mathrm{L}$ ) is uncertain and should be individualized.

\section{Conflicts of interest}

No potential conflict of interest relevant to this article was reported.

\section{References}

1. Crisafulli G, Aversa T, Zirilli G, Pajno GB, Corica D, De Luca F, et al. Subclinical hypothyroidism in children: when a replacement hormonal treatment might be advisable. Front Endocrinol (Lausanne) 2019;10:109.

2. Van Deventer HE, Mendu DR, Remaley AT, Soldin SJ. Inverse log-linear relationship between thyroid-stimulating hormone and free thyroxine measured by direct analog immunoassay and tandem mass spectrometry. Clin Chem 
2011;57:122-7.

3. Biondi B, Cappola AR, Cooper DS. Subclinical hypothyroidism: a review. JAMA 2019;322:153-60.

4. Cooper DS, Biondi B. Subclinical thyroid disease. Lancet 2012;379:1142-54.

5. Salerno M, Capalbo D, Cerbone M, De Luca F. Subclinical hypothyroidism in childhood - current knowledge and open issues. Nat Rev Endocrinol 2016;12:734-46.

6. Gopalakrishnan S, Chugh PK, Chhillar M, Ambardar VK, Sahoo M, Sankar R. Goitrous autoimmune thyroiditis in a pediatric population: a longitudinal study. Pediatrics 2008;122:e670-4.

7. Lee YJ, Jung SY, Jung HW, Kim SY, Lee YA, Lee SY, et al. Unfavorable course of subclinical hypothyroidism in children with Hashimotos thyroiditis compared to those with isolated non-autoimmune hyperthyrotropinemia. J Korean Med Sci 2017;32:124-9.

8. Brown RS. Autoimmune thyroiditis in childhood. J Clin Res Pediatr Endocrinol 2013;5 Suppl 1:45-9.

9. Nicoletti A, Bal M, De Marco G, Baldazzi L, Agretti P, Menabo S, et al. Thyrotropin-stimulating hormone receptor gene analysis in pediatric patients with non-autoimmune subclinical hypothyroidism. J Clin Endocrinol Metab 2009;94:4187-94.

10. Abe K, Narumi S, Suwanai AS, Adachi M, Muroya K, Asakura Y, et al. Association between monoallelic TSHR mutations and congenital hypothyroidism: a statistical approach. Eur J Endocrinol 2018;178:137-44.

11. Cassio A, Nicoletti A, Rizzello A, Zazzetta E, Bal M, Baldazzi L. Current loss-of-function mutations in the thyrotropin receptor gene: when to investigate, clinical effects, and treatment. J Clin Res Pediatr Endocrinol 2013;5 Suppl 1:2939.

12. De Marco G, Agretti P, Montanelli L, Di Cosmo C, Bagattini $\mathrm{B}$, De Servi M, et al. Identification and functional analysis of novel dual oxidase 2 (DUOX2) mutations in children with congenital or subclinical hypothyroidism. J Clin Endocrinol Metab 2011;96:E1335-9.

13. King K, O'Gorman C, Gallagher S. Thyroid dysfunction in children with Down syndrome: a literature review. Ir J Med Sci 2014;183:1-6.

14. Aversa T, Salerno M, Radetti G, Faienza MF, Iughetti L, Corrias A, et al. Peculiarities of presentation and evolution over time of Hashimoto's thyroiditis in children and adolescents with Down's syndrome. Hormones 2015;14:410-6.

15. Grossi A, Crinò A, Luciano R, Lombardo A, Cappa M, Fierabracci A. Endocrine autoimmunity in Turner syndrome. Ital J Pediatr 2013;39:79.

16. Deladoëy J, Ruel J, Giguère Y, Van Vliet G. Is the incidence of congenital hypothyroidism really increasing? A 20-year retrospective population-based study in Québec. J Clin Endocrinol Metab 2011;96:2422-9.

17. Buluş AD, Tiftik E. Evaluation of neurodevelopment of children with congenital hypothyroidism by the Denver Developmental Screening Test. J Pediatr Endocrinol Metab
2017;30:1061-6.

18. Reinehr T. Thyroid function in the nutritionally obese child and adolescent. Curr Opin Pediatr 2011;23:415-20.

19. Reinehr T, Andler W. Thyroid hormones before and after weight loss in obesity. Arch Dis Child 2002;87:320-3.

20. Gökdeniz E, Demir C, Dilek I. The effects of iron deficiency anemia on the thyroid functions. J Clin Exp Invest 2010;1:156-60.

21. Metwalley KA, Farghaly HS, Hassan AF. Thyroid status in Egyptian primary school children with iron deficiency anemia: relationship to intellectual function. Thyroid Res Pract 2013;10:91-5.

22. Afroz S, Khan AH, Roy DK. Thyroid function in children with nephrotic syndrome. Mymensingh Med J 2011;20:407-11.

23. Benvenga S, Vita R, Di Bari F, Fallahi P, Antonelli A. Do not forget nephrotic syndrome as a cause of increased requirement of levothyroxine replacement therapy. Eur Thyroid J 2015;4:138-42.

24. Lazar L, Frumkin RB, Battat E, Lebenthal Y, Phillip M, Meyerovitch J. Natural history of thyroid function tests over 5 years in a large pediatric cohort. J Clin Endocrinol Metab 2009;94:1678-82.

25. Wasniewska M, Salerno M, Cassio A, Corrias A, Aversa T, Zirilli G, et al. Prospective evaluation of the natural course of idiopathic subclinical hypothyroidism in childhood and adolescence. Eur J Endocrinol 2009;160:417-21.

26. Shrestha U, Gautam N, Agrawal KK, Jha AC, Jayan A. Iodine status among subclinical and overt hypothyroid patients by urinary iodine assay: a case-control study. Indian J Endocrinol Metab 2017;21:719-23.

27. Kang MJ, Hwang IT, Chung HR. Excessive iodine intake and subclinical hypothyroidism in children and adolescents aged 6-19 years: results of the Sixth Korean National Health and Nutrition Examination Survey, 2013-2015. Thyroid 2018;28:773-9.

28. Chemaitilly W, Cohen LE. Diagnosis of endocrine disease: endocrine late-effects of childhood cancer and its treatments. Eur J Endocrinol 2017;176:R183-203.

29. Rosene ML, Wittmann G, Arrojo e Drigo R, Singru PS, Lechan RM, Bianco AC. Inihibition of type 2 iodothyronine diodinase underlies the elevated plasma TSH associated with amiodarone treatment. Endocrinology 2010;151: 5961-70.

30. Tomer Y, Menconi F. Interferon induced thyroiditis. Best Pract Res Clin Endocrinol Metab 2009;23:703-12.

31. Benedetti MS, Whomsley R, Baltes E, Tonner F. Alteration of thyroid hormone homeostasis by antiepileptic drugs in humans: involvement of glucuronosyltransferase induction. Eur J Clin Phamacol 2005;61:863-72.

32. Van den Berghe G. Non-thyroidal illness in the ICU: a syndrome with different faces. Thyroid 2014;24:1456-65.

33. Marks SD. Nonthyroidal illness syndrome in children. Endocrine 2009;36:355-67.

34. Stockigt J. Assessment of thyroid function: towards an integrated laboratory--clinical approach. Clin Biochem Rev 
2003;24:109-22.

35. Favresse J, Burlacu MC, Maiter D, Gruson D. Interferences with thyroid function immunoassays: clinical implications and detection algorithm. Endocr Rev 2018;39:830-50.

36. Hattori N, Ishihara T, Matsuoka N, Saito T, Shimatsu A. Anti-thyrotropin autoantibodies in patients with macrothyrotropin and long-term changes in macro-thyrotropin and serum thyrotropin levels. Thyroid 2017;27:138-46.

37. Roelfsema F, Veldhuis JD. Thyrotropin secretion patterns in health and disease. Endocr Rev 2013;34:619-57.

38. Scobbo RR, VonDohlen TW, Hassan M, Islam S. Serum TSH variability in normal individuals: the influence of time of sample collection. W V Med J 2004;100:138-42.

39. Benvenga S, Di Bari F, Granese R, Antonelli A. Serum thyrotropin and phase of the menstrual cycle. Front Endocrinol (Lausanne) 2017;29;8:250.

40. Gary KA, Winokur A, Douglas SD, Kapoor S, Zaugg L, Dinges DF. Total sleep deprivation and the thyroid axis: effects of sleep and waking activity. Aviat Space Environ Med 1996;67:513-9.

41. Chaudhary V, Bano S. Thyroid ultrasound. Indian J Endocrinol Metab 2013;17:219-27.

42. Bauer AJ, Francis GL. Evaluation and management of thyroid nodules in children. Curr Opin Pediatr 2016;28:536-44.

43. Ittermann T, Thamm M, Wallaschofski H, Rettig R, Völzke H. Serum thyroid stimulating hormone levels are associated with blood pressure in children and adolescents. Clin Endocrinol Metab 2012;97:828-3.

44. Çatlı G, Kır M, Anık A, Yılmaz N, Böber E, Abacı A. The effect of $\mathrm{L}$ thyroxine treatment on left ventricular functions in children with subclinical hypothyroidism. Arch Dis Child 2015;100:130-7.

45. Tacito LHB, Pires AC, Yugar-Toledo JC. Impaired flowmediated dilation response and carotid intima-media thickness in patients with type 1 diabetes mellitus with a mean disease duration of 4.1 years. Arch Endocrinol Metab 2017;61:542-9.

46. Bachar GN, Dicker D, Kornowski R, Atar E. Epicardial adipose tissue as a predictor of coronary artery disease in asymptomatic subjects. Am J Cardiol 2012;110:534-53

47. Farghaly HS, Metwalley KA, Raafat DM, Algowhary M, Said GM. Epicardial fat thickness in children with subclinical hypothyroidism and its relationship to subclinical atherosclerosis: a pilot study. Horm Res Paediatr 2019;92:99-105.

48. Cerbone M, Capalbo D, Wasniewska M, Mattace Raso G, Alfano S, Meli R, et al. Cardiovascular risk factors in children with long-standing untreated idiopathic subclinical hypothyroidism. J Clin Endocrinol Metab 2014;99:2697-703.

49. Cerbone M, Bravaccio C, Capalbo D, Polizzi M, Wasniewska M, Cioffi D, et al. Linear growth and intellectual outcome in children with long-term idiopathic subclinical hypothyroidism. Eur J Endocrinol 2011;164:591-7.

50. Fiore E, Rago T, Provenzale MA, Scutari M, Ugolini C, Basolo F, et al. L -thyroxine- treated patients with nodular goiter have lower serum TSH and lower frequency of papillary thyroid cancer: results of a cross sectional study on 27,914 patients. Endocr Relat Cancer 2010;17:231-9. 